perhaps those remaining to be found in the coast country are both few and ráre. By way of compensation, however, certain Australian birds, the native companion, white ibis, and royal spoonbill, must now be included in the Papuan avifauna as at least temporary sojourners on the banks of the Fly River. It is noteworthy that these birds were found on the Fly River during the continuance in the north of Queensland of a drought which had driven them from their haunts proper and scattered them far and wide in search of water. Of the reptiles, on the other hand, a few new forms are distinguishable. These occur among the lizards. Two handsome snakes, Chondropython azureus and pulcher, have been added to the State collection of Papuan ophidians. On the whole, the vertebrate collection is subordinate in importance and interest to that of the insect division of the invertebrates. The whole of the insects collected were examined by the Entomological Department, and two reports on the Lepidoptera and Coleoptera are appended. From these it appears that several species both of butterflies and beetles are new to science. The collection contains in many instances a large series of examples of the same insect, which is all-important in the case of variable forms, whose unknown range of variation is a prolific source of error. Besides Lepidoptera and Coleoptera it contains many Hemipterous insects which have not yet been determined. The few forms of Mollusca procured on the Fly River have yielded but one new species, a remarkably fine Nanina.

\section{A MEDIUM FOR PRESERVING THE COLOURS OF FISH AND OTHER ANIMALS.}

UR readers may remember that Mr. Haly, Curator of the Colombo Museum, has for some years been making experiments so as to discover a medium which will preserve the colours of fish and other animals. We quote the following from the last Annual Report of the Colombo Museum :-

"In my last year's report I made some remarks on the use of carbolized oil as a mounting fluid for specimens already prepared by other means, the idea that it was a preservative in itself not having occurred to me. Further experiments this year seem to show (I do not like to speak too confidently in a climate like this, even with twelve months' experience) that it is one of the most perfect preservatives known both for form and colour.

"Coco-nut oil and carbolic acid freely mix in all proportions. The mixtures at present under trial are oil raised to the specific gravity of $10^{\circ}$ and $20^{\circ}$ below proof-spirit by the addition of acid. Whilst the gum and glycerine process is absolutely useless for any animals except certain families of fish, this mixture is good for every kind of vertebrate. The most delicate frogs are quite uninjured by it, and snakes undergo no change. The delicate plum-like bloom on the geckoes, the fugitive reddish tint on such snakes as Ablabes humberti, are beantifully preserved by it.

"Another most important use is in the preservation of large fish skins, which can be packed away in it for an indefinite period, and mounted when wanted. These skins do not require varnishing, neither do they turn brown, but although, of course, they do not preserve their sheen like fish in the oil itself, they always maintain a silvery and natural appearance, quite different from that of ordinary museum specimens. If ever we get a new fish gallery, a show of our large species prepared in this way would form a most effective exhibition.

"It appears also to be a most excellent preservative for Crustacea and the higher orders of Arachnids, and also for Centipedes, but it has hitherto proved a failure for marine inveriebrates in general. It must be remembered, however, that the perfect miscibility of the two liquids opens up endless possibilities. Its absolutely unevaporable nature makes it invaluable in a tropical climate, quite apart from its other qualities.

"With regard to this last remark I take the opportunity of stating that the acid enables coco-nut oil and turpentine to be mixed together. This forms a splendid microscopic fluid, in which objects may be allowed to soak without any previous preparation, and in which they become very transparent. A minute species of Crustacean, of the order Copepoda, and the leg of a fly, simply laid on a slide in a drop of this fluid and covered with an ordinary covering-glass, without any cell being made or cement employed, have lain on my table unaltered for the last ten months, and I cannot help thinking that such a medium as this cannot fail to prove a great boon to all workers with the microscope."

\section{SCIENTIFIC SERIALS}

American Fournal of Science, December.- On Percival's map of the Iura-Trias trap-belts of Central Connecticut, with observations on the up-turning, or mountain-making disturbance, of the formation, by James D. Dana.-The detection and determination of potassium spectroscopically, by F. A. Gooch and T. S. Hart. By dipping platinum coils of different sizes in a solution of the salt to be tested it was found possible to take up known quantities of material for introduction into the volatilizing flame employed. Experimenting in this manner with a single-prism spectroscope, it was found that of a milligram of potassium produced a line distinctly visible with a slit of $0.18 \mathrm{~mm}$., and $\frac{1}{1000} \mathrm{mgr}$. with a slit of $0.23 \mathrm{~mm}$. The test appears to be Jess delicate with potassium sulphate than when the chloride is used, and rather more delicate in the case of the carbonate. The red line of potassium was unmistakably seen when only $\frac{1}{2000}$ mgr. of potassium was introduced into the flame in the form of the carbonate. For quantitative determinations a standard solution, from which $\frac{1}{5} \sigma \mathrm{mgr}$. of potassium was taken by a certain platinum coil, was employed. The modus oferandi was to dilite the test-solution until the line given by the potassium contained in a coil-full was of the same brightness as that given by the same quantity of the standard solution. Remarkably consistent results were thus obtained. An interest. ing point brought out by the experiments is that the presence of sodium salts in the flame is of direct influence in strengthening the spectrum of potassium. - The ultra-violet spectrum of the solar prominences, by George E. Hale. This important paper was read at the last meeting of the British Association, and has been previously noted.-Phonics of auditoriums, by Ephraim Cutter. It is generally known that a well-constructed auditorium resonates certain sounds better than others, and that many clergymen accommodate their tone of speaking to the key-note of their church. Dr. Cutter has made observations on this point in four halls, and recommends those who control auditoriums to find the key-note and post up the result. Thus, an auditorinm at Saratoga Springs was tested in I89o, and a notice was put up, "The key-note of this hall is F."The secular variation of latitude, by George C. Comstock. This is a general account of the observations made at Greenwich, Pulkowa, Madison, and elsewhere, which indicate that the latitude of a single place is subject to a secular variation.-On the capture of comets by planets, especially their capture by Jupiter, by H. A. Newton.-Distribution of titanic oxide upon the surface of the earth, by F. P. Dunnington. An estimation has been made of the titanium in eighty different specimens of soil taken from different parts of the earth's surface. Soils from Virginia gave an average of I'57 per cent. of titanic oxide, and twenty-two samples from other portions of the United States gave an average of 0.85 per cent. The average proportion in air-dried soils from Oceania and Asia (I4 specimens) was 0.90 per cent., and I6 specimens from Europe gave 0.54 per cent. The eight remaining estimations were made on typical rocks of the localities which furnished the samples for analysis. - Notes on a Missouri barite, by C. Luedeking and H. A. Wheeler.-The contraction of molten rock, by C. Barus. A sample of diabase has been fused and allowed to cool slowly. The molten rock contracted regularly until a temperature of $1093^{\circ}$ was reached, when the diabase solidified with a sudden contraction of bulk. The density of the original rock was 3.0178 , and that of the glass obtained 2717 . The observations indicate that "structural rock texture is due to pressure, i.e. pressure induces a redistribution of molecules, such that the smallest specific volume possible under the given conditions may result."-Notes on Michigan minerals, by A. C. Lane, H. F. Keller, and F. F. Sharpless. The minerals considered are chloritoid, griinerite, and riebeckite.

\section{SOCIETIES AND ACADEMIES. LONDON.}

Royal Society, December 10.- "On a Compensated Airthermometer." By H. L. Callendar, M.A.

The air-thermometer is the ultimate standard to which all measurements of temperature have to be referred. It therefore becomes a question of considerable importance to determine 
what form of instrument is capable of giving the most accurate results.

For practical purposes there can be no doubt that electrical resistance thermometers, which are much easier to read and manipulate, and which are, at the same time, exceedingly constant over a very wide range, would be much more convenient as standard instruments. But for theoretical work it is always necessary to reduce their indications to the scale of absolute temperature.

With this object the writer has been for some years engaged in endeavouring to construct an air-thermometer which should be capable of reading to a degree of accuracy comparable with that attained by the use of electrical-resistance thermometers. This he believes that he has at length succeeded in securing by the adoption of the modified and compensated form of differ ential air-thermometer described in the paper.

The common and familiar form of differential air-thermomete consists essentially of two equal bulbs, communicating with opposite limbs of a $U$-tube of small bore containing sulphuric acid, which serves to indicare the difference of pressure between them. If the standard bulb be kept in melting ice, so that its temperature is constant, it is possible, by using a kathetomete microscope, to read small changes of temperature in the thermometric bulb with an accuracy of the order of a thousandth of a degree.

In order to make the instrument capable of reading over a wider range, it is only necessary to add an auxiliary bulb, as in the ordinary " constant-pressure" type of air-thermometer, into which the air from the thermometric bulb is allowed to dilate. The auxiliary bulb is provided with taps, through which mercury can be introduced or withdrawn in weighed quantities, to equalize the pressures. The dilatation of the air at constant pressure can be very accurately measured by weighing the mercury dis placed. This form of air-thermometer has the advantage of being entirely independent of barometric readings. A great deal of trouble is thus saved ; moreover, it is certain that a much greater degree of accuracy can be attained in this way in the measurement of a volume than in the measurement of a pressure by means of a mercury manometer, as in the "constant-volume" type of air-thermometer.

With almost every form of air-thermometer, some part of the air contained in the connecting tubes is necessarily exposed to temperatures different from those of the bulbs. In accurate work a correction must always be applied for this by calibrating the connecting tubes and estimating their mean temperature. This correction, however, is exceedingly troublesome to apply, and becomes a very serious source of uncertainty in attempting to work to a thousandth of a degree.

It is, perhaps, the greatest advantage of this particular form of differential air-thermometer, that this troublesome and uncertain correction can be completely eliminated both from the observations and from the calculations by simply duplicating the connecting tubes-that is, by making the thermometric and standard bulbs communicate with similar sets of connecting tubes fixed side by side in such a way that their mean temperatures are always equal. Provided that the two bulbs contain equal masses of air, and that their pressures are adjusted to equality, any change in the temperature of the connecting tubes will affect both equally, and will not, therefore, alter the reading of the pressure-gauge. ${ }^{1}$ In this way not only is the work of taking and reducing the observations immensely simplified, but the results are also rendered much more accurate.

The form of instrument above described is designed for the most accurate work. For rough purposes, and especially for limited ranges of temperature, for which the auxiliary bulb can be dispensed with, much simpler instruments may be constructed and compensated on similar principles.

In ordinary work it would be inconvenient to have to keep the standard bulb always at a constant temperature. The necessity for this may, however, be avoided by adjusting the quantity of sulphuric acid in the pressure gauge so that its expansion compensates for the increase of pressure in the standard bulb due to rise of temperature of the surrounding air. When the instrument is thus compensated, one of the tubes of the pressure gauge can be directly graduated in degrees of temperature. The indications are then as easy to read as those of a mercury thermometer. Such thermometers are very convenient for rough work at temperatures beyond the range of mercury

'The equations and conditions of compensation are fully given in the paper.

NO. I I 57 , VOL. 45] thermometers. They can be made with a range from $300^{\circ}-$ $500^{\circ} \mathrm{C}^{1}{ }^{1}\left(500^{\circ}-900^{\circ} \mathrm{F}\right.$.), and will read to a tenth of a degree at $40^{\circ} \mathrm{C}$. They are practically free from change of zero, and if properly compensated their indications are very reliable. Since the connecting tubes are compensated, they can be made of considerable length, and even of flexible material, such as compotubing, wtthout much loss of accuraey. This is often a matter of great convenience, especially in high temperature work.

"Repulsion and Rotation produced by Alternating Electric Currents." By G. T. Walker, B.A., B.Sc., Fellow of Trinity College, Cambridge. Communicated by Prof. J. J. Thomson.

The author described the following experiment :-A sheet of copper is placed so as to half cover an alternating magnetic pole. Upon this, near the pole, is laid a hollow sphere of copper. The electro-magnetic action produces a couple so powerful that the friction of rotation is overcome, and the sphere spun round.

In order to throw light on this, after a theorem in $\$ 2$ as to the kind of currents set up in a conductor, I have considered a number of cases. A thin circular infinite cylindrical shell lies in an alternating field of currents parallel to its axis, and the couple upon it is found. The result is applied to give the couples on two such shells in the presence of a parallel current and of a pair of currents forming an electro-magnet.

The couple in action upon a thin spherical shell in a general periodic field has next been found, and is applied to give the couples on two thin shells under the influence of -

(i.) An alternating current in a straight infinite wire.

(ii.) A pair of such currents forming an electro-magnet.

(iii.) An alternating magnetic pole.

(iv.) An alternating electro-magnet of very short length.

Chemical Society, November 19,-Sir Henry Roscoe, F.R.S., in the chair. - The following paper was read:-Iron carbonyl, by L. Mond, F.R.S., and Dr. Langer. An account of this paper has already appeared in NATURE of November 26 (p. 89). - A lecture was then delivered on colour photometry, by Captain Abney, C.B., F.R.S. According to the lecturer the colour of a body, when viewed in a light of standar quality, is known when $(a)$ its luminosity, $(b)$ its hue, and $(c)$ its purity, or the extent to which it is freed from admixture with white light, are known and expressed by numbers. The luminosity of a colour can be given in absolute number by referring it to the standard of white. The standard of white employed is a surface coated with zinc oxide. It is also necessary to employ a standard light in these experiments, and the light recommended is that from the crater of the positive pole of the electric light, or from a petroleum lamp, when the illumination need not be so intense. The luminosity of the pure spectrum colours may be measured by what the author calls the colour patch apparatus, which is described in the Phil. Trans., 1886 , and in his book on "Colour Measurement and Mixture." The luminosity of a colour is not the same when viewed from all parts of the eye. The luminosity of any pigment on paper can be found by rotating it with two or three colours, red, emeraldgreen, and ultramarine. The colour of a pigment can be referred to the spectrum colours by measuring the absorption. The mixture, in varying proportions, of red, green, and violet of the spectrum, makes white. Any other colour can be matched by the mixture of the same three colours. Since three colours will make white, and the same three colours will make a match with an impure colour, every colour in nature can evidently be matched by mixing not more than two of these colours with a certain proportion of white light, and if these colours be red and green, or green and violet, the colour can be matched by one spectrum colour and white light, since there is some intermediate colour which has the same hue as the mixture of these two colours. Hence any colour may be expressed in terms of white light and one spectrum colour, the latter in wave-lengths and the former in percentage of luminosity. The lecturer performed experiments in illustration of all the points brought forward. The importance of using some uniform light was insisted upon throughout. In conclusion the lecturer claims to have demonstrated that the reference of colours to numbers is not only possible but easy.

December 3.--Prof, A. Crum Brown, F.R.S., in the chair.The following papers were read :- Phosphorous oxide, Part ii. I An air-pyrometer and also a long-distance thermometer of this pattern are made by Mr. J. J. Hicks, of Hatton Garden, E.C. 
by T. E. Thorpe, F.R.S., and A. E. Tutton. In this paper the authors have continued their description of the properties of phosphorous oxide, $\mathrm{P}_{4} \mathrm{O}_{6}$. In their first paper they state that phosphorous oxide becomes red on exposure to light. They have now obtained the oxide in large crystals, unaffected by light, by exposing the freshly-distilled oxide to sunshine for several months at a time, and decanting the melted oxide from the red phosphorus produced. Large crystals of the oxide are also obtained by sublimation in a vacuum, and these are unaffected by light so long as they retain their crystalline form. The authors also describe the reactions of the oxide with the following substances: bromine, iodine, hydrogen chloride, sulphur, sulphur trioxide, sulphuric acid, sulphur chloride, ammonia gas, nitrogen peroxide, phosphorus pentachloride, and phosphorus trichloride. The following substances are apparently without action on phosphorous oxide : hydrogen, phosphoretted hydrogen, carbon monoxide, carbon dioxide, sulphur dioxide, nitrogen, nitric acid, cyanogen, and ethylene.-Frangulin, Part ii., by T. E. Thorpe, F.R.S., and Dr. A. K. Miller The authors have prepared frangulin more nearly in a state of purity than was previously possible. They find that crude frangulin contains a substance isomeric with emodin, which ciings to it persistently, and is very difficult to remove. They have succeeded in proving the correctness of Schwabe's formula, $\mathrm{C}_{21} \mathrm{H}_{20} \mathrm{O}_{9}$, for frangulin. On hydrolysis it yields emodin, $\mathrm{C}_{15} \mathrm{H}_{10} \mathrm{O}_{5}$, and rhamnose, $\mathrm{C}_{6} \mathrm{H}_{12} \mathrm{O}_{5}$, according to the equation $\mathrm{C}_{21} \mathrm{H}_{20} \mathrm{O}_{9}+\mathrm{H}_{2} \mathrm{O}=\mathrm{C}_{15} \mathrm{H}_{10} \mathrm{O}_{5}+\mathrm{C}_{6} \mathrm{H}_{12} \mathrm{O}_{5}$. The structure and chemistry of flames, by A. Smithells and $\mathrm{H}$. Ingle. The authors have been engaged for 'twelve months in investigating the chemistry of flames produced by burning known hydrocarbons, and are still continuing the experiments. If a long glass tube be fitted over the metal tube of a Bunsen burner so as to form a wider continuation of it, and if the gas he carefully regulated, it is possible to divide the flame into two cones, one of which remains at the top of the tube, and the other oscillates inside the tube. By heating the glass tube at one point so as to increase at that point the rate of inflammation, it is possible to fix the oscillating inner cone-that is, to prevent its re-ascent. The same result is obtained by narrowing the bore of the glass tube at one point, so as to diminish the rate of inflammation, i.e. to prevent the descent of the inner cone past that point. In this way the two cones can be kept any distance apart for any length of time. This permits of the aspiration of the gases from the space between the cones with. out any chance of admixture of outside air or of products of combustion from the upper cone. The apparatus used by the authors is described. The flames of liquid hydrocarbons were examined by charging air with the vapour of the liquid, and afterwards mixing this vapour-charged air with more air in suitable proportions. The hydrocarbons examined were ethylene, methane, pentane, heptane, and benzene. The results obtained show that the products of combustion of the first cone are essentially $\mathrm{CO}_{2}, \mathrm{H}_{2} \mathrm{O} . \mathrm{CO}$ and $\mathrm{H}_{2}$, and that the second cone is due to the combustion of the $\mathrm{CO}$ and $\mathrm{H}_{2}$ with the external air. These results are in harmony with the con clusions of Blochmann, and with the work of Dalton on the explosion of methane and ethylene with oxygen in quantities insufficient for complete combustion. The authors point out : (I) that, even in excess of oxygen, carbon turns preferentially to $\mathrm{CO}$ and not to $\mathrm{CO}_{2} ;(2)$ that the heat of combustion of gaseous carbon to $\mathrm{CO}$ is probably greater than that of hydrogen to $\mathrm{H}_{2} \mathrm{O}$; (3) that, according to Dalton, $\mathrm{CH}_{2}$, when burnt with its own volume of oxygen, gives products represented in the equation $\mathrm{CH}_{2}+\mathrm{O}_{2}=\mathrm{CO}+\mathrm{H}_{2} \mathrm{O}+\mathrm{H}_{2}$. But as the two substances, $\mathrm{CO}$ and $\mathrm{H}_{2} \mathrm{O}$, act upon one another, $\mathrm{CO}+\mathrm{H}_{2} \mathrm{O} \rightleftarrows \mathrm{CO}_{3}+\mathrm{H}_{2}$, the case is one of rever:ible change, and four products will result -viz. $\mathrm{CO}_{2}, \mathrm{H}_{2} \mathrm{O}, \mathrm{CO}$, and $\mathrm{H}_{2}$. They have succeeded in divid. ing into two cones the flame produced by admixture of air with cyanogen; the products of the inner cone were found to consist of 2 vols. of $\mathrm{CO}$ and $\mathrm{I}$ vol. of $\mathrm{CO}_{2}$. - Note on the structure of luminous flames, by A. Smithells. A brief summary of the various views that have been held on this subject is given. The author would describe a luminous flame as follows: (I) an outer sheath or mantle, with (2) an inner, bright blue portion, visible at the base of the flame-these two parts correspond respectively to the outer and inner flame cones of a Bunsen flame, and mark the region where the coal gas or candle gas is burning with a large quantity of air; (3) the yellow luminous part, where the heat of the parts (I) and (2) is decomposing hydrocarbons, setting free carbon which rapidly glows and burns ; (4) the dark inner region, consisting of unburned gas, -The existence of the mydatic alkaloid hyoscyamine in lettuce, by T. S. Dymond. The alkaloid was obtained from the commercial extract of wild lettuce, of the edible plan known as cos lettuce, and from a specimen of the dried flowering plant of wild lettuce. It was found to have approximately the same melting-point and other properties as hyoscyamine, the poisonous mydatic alkaloid existing in belladonna, henbane, and other plants belonging to the natural order Solanacee. The aurichloride melted at $159^{\circ} .75$, and on analysis gave results corresponding to the formula $\mathrm{C}_{17} \mathrm{H}_{23} \mathrm{NO}_{3} . \mathrm{HAuCl}_{4}$. - Cryptopine, by D. Rainy Brown and Dr.W. H. Perkin, Jun., F.R.S. The authors have commenced an investigation on the rare alkaloid cryptopine, which occurs in small quantity in opium. Analyses of the base and of the oxalate confirm the results of Hesse, and show that cryptopine has the formula $\mathrm{C}_{21} \mathrm{H}_{23} \mathrm{NO}_{5}$. On oxidation with permanganate it yields, among other products, metahemipinic acid (m.p. $179^{\circ}-180^{\circ}$ ). It contains only two methoxy-groups, as shown by its behaviour with hydriodic acid, these two groups being situated in that part of the molecule which is c snverted to metahemipinic acid on oxidation. - The action of sodium on ethereal salts, Part iii. benzylic orthotoluate, by R. W. Hodgkinson. When benzylic orthotoluate is heateil to $200^{\circ}$ and sodium dissolved in it, the temperature rises to $250^{\circ}$, when an oil distils over. This oil was separated into toluene, benzoyl alcohol, and a small quantity of the original salt. The sodium salt in the retort gave pure orthotoluic acid, unchanged benzylic orthotoluate, and a substance of the composition $\mathrm{C}_{22} \mathrm{H}_{20} \mathrm{O}_{2}$. The author is continuing the experiments. - The gas-volumeter and gravivolumeter, by $G$. Lunge. A reply to Prof. Japp's reply to the author's criticisms (Ber. xxiv. I656). - The action of sulphuric acid on the bromiles of hydrogen, potassium. and sodium, by F. T. Addyman. The author has sought to determine the extent to which hydrogen bromide is oxidized by sulphuric acid under varying conditions of mass and dilution.-The iodometric estimation of chlorine, by Dr. G. McGowan. Finkener has stated that Bunsen's method when applied to chlorates gives less than the theoretical amount of chlorine. The author describes experiments which prove the accuracy of Bunsen's method, and suggests that Finkener's error aruse from a slight loss of chlorine.

Mathematical Society, December Io.-Prof. Greenhill, F.R.S., President, in the chair. - The President announced the recent decease of Prof. Wolstenholme, with whom he had been associated at Cooper's Hill, and paid a feeling tribute to his memory, in the course of which he touched upon Prof. Wolstenholme's mathematical work. - The following communications were made:The equations of propagation of disturbances in gyrostatically loaded media, by J. Larmor. In the first instance an extended body is imagined, in Sir W. Thomson's manner, as built up of rigid solid elements, each containing a cavity in which is mounted a rapidly rotating fly-wheel; and this structure is then pushed to the limit when it gives a continuous elastic medium. Such a medium possesses at each point two coefficients of inertia - a scalar one which is specified as the density, or mass per unit volume, and a vector one which measures the angular momentum per unit volume. As we can thus imagine a solid with two per. sistent constants of inertia, and as it is apparently not possible to have more than these two, it seems worth while to formally express the general equations of elasticity that will apply to such a body. It turns out that, for a homogeneous body having (LMN) as its vector constant of inertia, there must be added to the force per unit volume due to the tractions of the surrounding parts a term of which the $x$ component is

$$
-\frac{1}{4}\left(\mathrm{~L} \frac{d}{d x}+\mathrm{M} \frac{d}{d y}+\mathrm{N} \frac{d}{d z}\right) \frac{d}{d t}\left(\frac{d v}{d z}-\frac{d w}{d y}\right),
$$

(uvzu) being the displacement. The waves of permanent type in such a medium, otherwise isotropic, are all circularly polar. ized, the coefficient of rotation being simply proportional to the component of the rotary inertia in the directior if propagation. If the rotary apparatus is more complex than a simple fly-wheel, so as to have free periods of its own, these will be indicated by anomalous rotatory dispersion, and the equations will require modification. It is pointed out that of the three terms put forward by Sir G. Airy as competent to explain the magnetic rotation of light, the one verified by Verdet enters simply in the above manner; while the others, which do not by themselves agree with experiment, imply absolute time-constants, such as

$$
\text { NO. I I } 57 \text {, VOL. 45] }
$$


free periods of molecular vibration, associated with the rotational property. - On the theory of elastic wires, by A. B. Basset, F.R.S. The stresses which act across any section of a thin elastic wire consist of a tension along the tangent, two shearing stresses along the principal normal and binormal respectively, and three couples about these directions. By resolving parallel to these directions, and taking moments about them, six equations can be obtained, which determine the stresses, when the unstrained form of the wire is given. The values of the three couples can be obtained by a method similar to that employed in my papers on thin elastic plates and shells; and when the wire is inextensible, these values lead to four equations connecting the displacements of any point on the axis, together with a quantity $\beta$, such that $d \beta / d s$ measures the twist per unit of length. The torsional vibrations of a complete circular wire are afterwards investigated; and it is shown that they consist of a long period and a short period; that the gravest note is due to the torsional vibrations, and its frequency is proportional to the square root of $18 n q c^{2} / \rho a^{4}(8 n+q)$, where $a$ and $c$ are the radii of the axis and cross-section respectively, $\rho$ the density, $n$ the rigidity, and $q$ is Young's modulus. - Researches in the calculus of variations ii., discrimination of maxima and minima solutions when the variables are connected by algebraical equations, the limits being supposed fixed, by E. P. Culverwell. - Note on the algebraic theory of elliptic transformation, by J. Griffiths.-Messrs. A. B. Kempe and J. Hammond made short impromptu communications, and also took part with Messrs. Larmor, Basset, Forsyth, Love, S. Roberts, and the President, in the discussions on the papers.

Royal Meteorological Society, December 16.-Mr. Baldwin Latham, President, in the chair.-Mr. W. Marriot gave the results of the investigation undertaken by the Society into the thunderstorms of 1888 and 1889 , which he illustrated by a number of lantern slides. The investigation was originally confined to the south-east of England, but as this district was found to be too circumscribed, it became necessary to include the whole of England and Wales. After describing the arrangements for collecting the observations, and the methods adopted for their discussion, $\mathrm{Mr}$. Marriott gave statistics showing the number of days on which thunderstorms occurred at each station the number of days of thunderstorms in each month for the whole country; the number of days on which it was reported that damage or accidents from lightning occurred; and also the number of days on which hail accompanied the thunderstorms. In 1888 there were 113 days, and in 1889 I 23 days on which thunderstorms occurred in some part of the country. The number of days with damage by lightning was 33 in 1888 , and 38 in 1889 ; and there were 56 days in each year on which hail accompanied the thunderstorms. The tables of hourly frequency show that thunderstorms are most frequent between noon and 4 p.m., and least frequent between $\mathrm{I}$ a.m. and $7 \mathrm{a} . \mathrm{m}$. Thunderstorms appear to travel at an average rate of about 18 miles per hour in ill-defined low barometric pressure systems, but at a higher rate in squally conditions. The author is of opinion that individual thunderstorms do not travel more than about 20 miles; and that they take the path of least resistance, and are consequently most frequent on flat and low ground. Detailed isobaric charts, with isobars for two-hundredths of an inch, were prepared for $9 \mathrm{a} . \mathrm{m}$. and $9 \mathrm{p} . \mathrm{m}$. each day for the month of June 1888. An examination of these charts showed that, instead of the pressure being so very ill-defined as appeared on the daily weather charts, there are frequently a number of small but distinct areas of low pressure, or cyclones, with regular wind circulation; and that these small cyclones passed over the districts from which thunderstorms were reported. Sometimes it is not possible to make out well-formed areas of low pressure from two-hundredths of an inch isobars, but there is a deflection of the wind which shows that there is some disturbing cause and thunderstorms have usually occurred in that immediate neighbourhood. The author believes that the thunderstorm formations are small atmospheric whirls-in all respects like ordinary cyclones; and that the whirl may vary from I mile to Io miles or more in diameter. There are frequently several whirls near together, or following one another along the same track. The numerous oscillations in the barometric curve are evidently due to the passage of a succession of atmospheric whirls; and it appears that lightning strokes are most frequent when these oscillations are numerous.-Mr. F. J. Brodie read a paper on the prevalence of fog in London during the twenty years 187 to 1890 . The popular notion that November is par excellence a NO. I I 57 , VOL. 45 month of fog is not confirmed by the figures given by the author. The number of fogs in that month is, if anything, slightly less than in October or January, and decidedly less than in December, the last-mentioned month being certainly the worst of the whole year. The latter part of the winter is not only less foggy than the earlier part, but is clearer than the autumn months. In February the average number of days with fog is only 6.6 , as against 8.9 in January, 10.2 in December, $9^{\circ} 2$ in October, and 8.8 in November.

Linnean Society, December 17.- Prof. Stewart, President, in the chair.-Mr. G. C. Druce exhibited specimens of Sagina maritima, Don MS., var, alpina, Syme, rathered on steep rocky places on the Cairngorms, and of Illecebrum verticillatum, Linn., found near Wellington College, Berks.-Dr. R. C. A. Prior exhibited some fruits of the baobab (Adansonia), and an undetermined species of palm, which had been sent from Matabele Land as good to eat, under the misleading names of " cream of tartar fruit" and "wild orange." He read an extract from Oates's "Matabele Land," describing the natural growth and appearance of the baobab as observed in that country. - The Hon. W. B. Espeut exhibited some nests of humming-birds from Jamaica, and pointed out the variety of materials used by the same species, though placed in the same tree (a mangrove), the coloration in some cases being protective, in others not. - A paper was then read on the occurrence of two species of Crustacea belonging to the sub-order Cumacea in New Zealand, whence none had been previously described. The author gave the result of his dredging in the Bay of Islands in the north, and in the inlets of Stewart Island in the south, and furnished drawings and descriptions of the species referred to. - A paper on the development of the head of the imago of Chironomus, by Prof. L. C. Miall and A. R. Hammond, was read by $\mathrm{Mr}$. Hammond, accompanied by a series of illustrations with the oxyhydrogen lantern. The subject was introduced by a brief sketch of the life-history of the insect in its three stages, followed by detailed descriptions of the head both of the larva and of the imago. The history of the epidermic invaginations, by which the imaginal head is formed within the larval head and prothorax, was then followed out to its consummation in the development of the fly. The lantern arrangements were successfully carried out by Mr. Frederick Enock.

\section{PARIS.}

Academy of Sciences, December 2I.-M. Duchartre in the chair.-List of prizes awarded to successful competitors in I891 :-Geometry.-Prix Francour, M. Mouchot; Prix Poncelet, M. Humbert. Mechanics.-Extraordinary Prize of 6000 francs : this was divided into four, two principal prizes of equal amount to MM. Pollard and Dudebout, one to M. Guyon, and the fourth to M. Chabaud-Arnaud. Prix Montyon, M. Caméré. Prix Plumey, M. de Maupeou. Prix Dalmont, M. Considère ; MM. Autonne and Ocagne being given honourable mention. Astronomy.-Prix Lalande, M. G. Bigourdan. Prix Damoiseau (not awarded). Prix Valz, Prof. Vogel. Prix Janssen, M. G. Rayet. Physics.-Prix La Caze, M. J. Violle. Statistics.Prix Montyon, M.M. Cheysson and Toqué. Chemistry.-Prix Jecker, MM. Béhal and Meunier. Prix La Caze, M. A. Joly. Geoloyy.-Prix Delesse, M. Barrois. Botany.-Prix Bordin, M. Léon Guignard. Prix Desmazières, M. Auguste-Napoléon Berlese. Prix Montagne, M. Henri Jumelle. Prix Thore, MM. J. Costantin and L. Dufour. Anatomy and Zoology.Grand Prix des Sciences Physiques, M. Jourdan. Prix Bordin, M. Beauregard. Prix Savigny, Dr. Lionel Faurot. Prix Da Gama Machado (not awarded). Medicine and Surgery.-Prix Montyon, divided between MM. Dastre, Duroziez, and Lannelongue; mentions were accorded to MM. Sanchez-Toledo and Veillon, to M. Soulier, and M. Zambaco ; and citations to MM. Arthaud and Butte, M. Batemann, MM. Bloch and Londe, M. Catsaras, M. Debierre, M. Garnier, M. Gautrelet, and M. Netter. Prix Barbier, M. Tscherning; mentions were accorded to MM. Delthil and Dupuy. Prix Bréant (not awarded). Prix Godard, M. Porier ; honourable mention to Dr. Wallich. Prix Chaussier, Dr. Brouardel; honourable mention to the late M. E. Duponchel. Prix Bellion, divided between MM. Carlier and Mireur. Prix Mère, M. Frédéric Courmont. Prix Lallemand, divided between MM. Gilles de la Tourette, H. Cathelineau, and F. Raymond; honourable mentions were accorded to MM. Legrain, Debierre, and Le Fort, Bruhl, Sollier, and Colin. Physiology.-Prix Montyon, MM. Bloch and Carpentier ; mentions were accorded to MM. Hédon and Lesage. Prix La Caze, 
M. S. Arloing. Prix Pourat, M. Gley, Prix Martin-Damourette, M. Gley. Physical Geosraphy.-Prix Gay (not awarded). General Prises. - Prix Montyon (unhealthy industries): the principal portion of this prize was awarded to M. Gréhant, and the remainder was divided equally between MM. Bay and Brousset; honourable mention was made of MM. Bédoin and Lechien. Prix Cuvier, the Geological Survey of the United States. Prix Frémont, M. Émile Rivière. Prix Gegner, M. Paul Serret. Prix Jean Reynaud, the late M. George-Henri Halphen. Prix Petit d'Ormoy (Sciences Mathématiques), M. Edouard Goursat. Prix Petit d'Ormoy (Sciences Naturelles), M. Léon Vaillant. Prix de la Fondation Leconte : a grant was accorded to M. Douliot. Prix Laplace, M. Champy.-The following prizes were proposed for the years $1892-1896:-$ Geometry.-Grand Prize for Mathematical Sciences : determination of the number of prime numbers inferior to a given quantity. Prix Bordin: study of the surfaces of which the linear elements may be reduced to the form

$$
d s^{2}=[f(u)-\phi(\nu)]\left(d u^{2}+d \nu^{2}\right) .
$$

Prix Bordin: applications of the general theory of Abelian functions to geometry. Prix Francoeur. Prix Poncelet. Mechanics. - Extraordinary Prize of 6000 francs : any improvements tending to increase the efficiency of the French naval forces. Prix Montyon. Prix Plumey. Prix Dalmont. Prix Fourneyron: historical, theoretical, and practical study of the bursting of fly-wheels. Astronomy-Prix Lalande. Prix Damoiseau: improvements of the lunar theory with reference to secular inequalities caused by planets; to see also if any sensible inequalities exist in addition to those already known. Prix Damoiseau : improvements in the methods of calculating perturbations of asteroids which are necessary for the representation of their position within a few minutes of arc, in an interval of fifty years; also to construct numerical tables which will allow the quick determination of the principal parts of the perturbations. Prix Valz. Prix Janssen. Physics.-Prix L. La Caze. Statistics.-Prix Montyon. Chemistry.-Prix Jecker. Prix L. La Caze. Mineralogy and Geology. - Grand Prix des Sciences Physiques: an exhaustive study of a question relative to the geology of a part of France. Prix Bordin : the genesis of rocks, exemplified by experimental synthesis. Prix Vaillant : applications of the examination of optical properties to the determination of mineral species and rocks. Prix Delesse. Prix Fontannes. Botany.Prix Barbier, Desmazières, Montagne, de la Fons Melicocq, and Thore. Agriculture.-Prix Morogues. Anatomy and Zoology._Prix Thore, Savigny, and Da Gama Machado. Medicine and Sursery.-Prix Montyon, Barbier, Bréant, Godard, Serres, Chaussier, Parkin, Bellion, Mège, Dusgate, and Lallemand. Physiology.-Prix Montyon. Prix L. La Caze. Prix Pourat: experimental and chemical researches on the inhibition phenomena of the nervous shock. Prix Pourat : researches on the effects of subcutaneous or intra-vascular injections on the normal liquids of the organism or on liquid extracts from different tissues or organs. Prix Martin-Damourette. Fhysical Geography.-.Prix Gay : study of terrestrial magnetism, and, in particular, the distribution of the magnetic elements in France. Prix Gay : study of the trajectory of cyclones moving from North America or the West Indies. General Prizes.Prix Montyon (unhealthy industries), Cuvier, Trémont, Gegner, Delalande-Guérineau, Jean Reynaud, Jérome Ponti, Petit D'Ormoy, Leconte, Tchihatchef, and Laplace.

Brussels.

Academy of Sciences, October IO.-M. F. Plateau in the chair. - Note on a number of Hyperoodons stranded in the Thames and on the Normandy coast, by P. J. Van Beneden.Study of heat and light phenomena accompanying electrolysis, by E. Lagrange et Hoho. In an electrolyte of dilute sulphuric acid a positive electrode having an area of $\mathrm{x} 8 \mathrm{osq} . \mathrm{cm}$. was immersed, whilst the negative electrode consisted of a wire of copper 0.25 $\mathrm{mm}$. in diameter, submerged to a depth of $0.5 \mathrm{~mm}$. below the leve of the liquid. On passing a current from accumulators through the electrolyte, the ordinary phenomena of electrolysis were observed. When the electromotive force was increased, a kind of decrepitation, resembling the fizzing noise which is heard when drops of water fall on a hot metal plate, was produced at the negative electrode. The liquid about this electrode appears to be in a state of ebullition. The phenomena increased in distinctness as the difference of potential between the negative electrode, and a point in the liquid $3 \mathrm{~mm}$. from it, approached
16 volts. At intervals, when the difference of potential had reached $\mathrm{i} 6$ volts, a number of luminous points were produced between the electrode and the liquid, and their frequency was found to increase with the difference of potential. The author has studied the phenomena, using electrodes of $\mathrm{Pt}, \mathrm{Cu}, \mathrm{Zn}, \mathrm{Sn}, \mathrm{Fe}$, and $\mathrm{C}$ of different diameters, and electrolytes of different degrees of dilution and different natures. He finds, among other things, that the phenomena commence when the electromotive force is the same (for a given degree of acidity) whatever the nature of the electrolyte. The intensity of the current increases, creteris paribus, with the sections of the electrodes, and varies with the nature of the electrode. For the same degree of acidity, the same electrode, and the same amount of immersed surface, the intensity of the current tends to remain constant, although the electromotive force varied from 76 to 98 volts.--On the case in which two hemihedric conjugate forms are not superposable; conditions necessary and sufficient for a polyhedron to be superposable on its image seen in a plane mirror ; possible existence in crystals of a class of hemihedra giving superposable conjugate forms, although possessing neither centre nor plane of symmetry; direct and inverse symmetry; tetrahedric group of the quadratic system represented by $\Lambda_{-4}$, by C. Cesaro.

\section{BOOKS AND PAMPHLETS RECEIVED.}

Books.-Die Elementarstructur und das Wachsthum der Lebenden Substanz: Dr. J. Wiesner (Wien. Hölder).-Magnetism and Electricity; and edition, elementary stage: J. Spencer (Percival).-Arithmetic for Schools: C. Smith (Cambridge University Press). - The Story of the Hills : Rev. H. N. Hutchinson (Seeley). - A History of Epidemics in Britain from A.D. 66 to the Extinction of the Plague: C. Creighton (Cambridge University Press).-Indigestion: Dr. T. Dutton (Kimpton).-Studies in Ratcatching H. C. Barkley (Murray). - The Century Dictionary, 6 vols. (Unwin). - Yearbook of Pharmacy, r801 (Churchill). - Societa Reale di Napoli; Atti della book of Pharmacy, 189 (Churchill). - Societa Reale di Napo!i ; Atti della Reale Accademia delle Scienze Fisiche e Matematiche, serie seconda, vol. 4 (Napol1).- Theory of Heat : J. Clerk Maxwell, Ioth edition (Longmans).Journeys in Persia and Kurdistan, 2 vols. : Mrs. Bishop (Murray), The Fauna of British India: Mammalia, part 2: W. T. Blanford (Taylor and Francis).- The Collected Mat

PAMPHLETs.-Old Glasgow, Greater Glasgow : J. B. Russell, - The PAMPHLETS. Old Glasgow, Greater Glasgow: J. B. Russell. - The
Character and Influence of the Indian Trade in Wisconsin: Dr. F. J. Turner (Balt).

\section{CONTENTS.}

PAGE

The Physical Theory of Solution. By J. W. R. . . 193

Colour Blindness . . . . . . . . . . . . . 195

A Meteorological Guide-book . . . . . . 196

Our Book Shelf:-

"Chambers's Encyclopædia," Vol. VIII. . . . . . I96

Huxley: "La Place de l'Homme dans la Nature" . 197

\section{Letters to the Editor:-}

Smithsonian Standards for Physical Apparatus. - Prof.

S. P. Langley ... . I97

Pigment in Yellow Butterflies.-F. Gowland Hopkins . . . .

The Chromosphere Line $\lambda 66769$. -Prof. C. A. Young . . . . 198

Grafts and Heredity.-Prof. George Henslow . . 198
Mental Arithmetic.-Dr, K. Haas .

The Migration of the Lemming.-W. 'DuppaCrotch

The Recent Earthquake in Japan.-Prof. F.-A. Forel

On the Virial Equation for Gases and Vapours. By

Prof. P. G. Tait

On the Relation of Natural Science to Art. 1. By

Prof. E. du Bois-Reymond, F.R.S.

Telescopic Objectives. (Illustrated.) By A. Fowler 204

Notes . . . . . . . . . . . . . 207

Our Astronomical Column:-

The Secular Variation of Latitudes . . . . . . . . 210

The Rotation of Venus . . . . . . . . 210

Stars having Peculiar Spectra. 210

The Tower of Babel and the Confusion of Tongues.

By Theo. G. Pinches . . . . . . 210

A Year's Scientific Work in New Guinea

A Medium for Preserving the Colours of Fish and

other Animals

Scientific Serials

Societies and Academies........ . 212

Societies and Academies ......... $2 \mathrm{I} 2$

Books and Pamphlets Receiveo . . . . . . . . 2 I6

NO. 1 I 57 , VOL. 45] 